\title{
A INSTITUCIONALIZAÇÃO DO RACISMO CONTRA NEGROS(AS) E AS INJÚRIAS RACIAIS NO ESPORTE PROFISSIONAL: O CONTEXTO INTERNACIONAL
}

\author{
THE INSTITUTIONALIZATION OF RACISM AGAINST BLACK PEOPLE \\ AND RACIAL SLURS IN PROFESSIONAL SPORTS: THE \\ INTERNATIONAL CONTEXT C己 \\ LA INSTITUCIONALIZACIÓN DEL RACISMO CONTRA NEGROS Y LOS \\ INSULTOS RACIALES EN EL DEPORTE PROFESIONAL: EL CONTEXTO \\ INTERNACIONAL C P
}

doi' https://doi.org/10.22456/1982-8918.104354

D Lennon Giulio Santos de Farias*<lennon.giulio@gmail.com>

(iD Léo Barbosa Nepomuceno* <leobnepomuceno@hotmail.com>

(D) Luiz Sanchez Neto*<luizitosanches@yahoo.com>

(D) Eduardo Vinícius Mota e Silva*<eduardo.silva@ufc.br>

\footnotetext{
*Universidade Federal do Ceará. Fortaleza, CE, Brasil.
}

\begin{abstract}
Resumo: O racismo é um fenômeno sociocultural que tem notável expressão nos campos esportivos. O objetivo desta pesquisa foi analisar a produção científica internacional sobre o racismo nos esportes profissionais publicada entre 2008 e 2018. A busca foi realizada em duas bases de dados: Portal da Capes e revistas indexadas na área de avaliação "Educação Física" da Plataforma Sucupira. Foram selecionados 65 artigos os quais são analisados a partir das categorias "injúria racial" e "racismo institucional". Vários casos de injúria racial são analisados e ilustram formas como o racismo tem colocado obstáculos às trajetórias de atletas negros em diversas modalidades. No plano institucional, são analisadas campanhas contra o racismo, bem como formas racistas de discriminação presentes em esportes como futebol, basquete, beisebol e futebol americano. Destacam-se a variedade de enfoques, a relevância dos estudos e a importância da temática para o enfrentamento do racismo nos campos esportivos estudados.
\end{abstract}

Palavras chave: Racismo. Difamação. Opressão social. Atletas.
Recebido em: 16-06-2020 Aprovado em: 23-08-2020 Publicado em: 09-10-2020

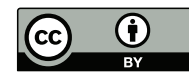

Este é um artigo publicado sob a licença Creative Commons Atribuição 4.0 Internacional (CC BY 4.0).

eISSN: 1982-8918 


\section{INTRODUÇÃO}

O presente trabalho versa sobre o fenômeno do racismo no contexto esportivo e suas variadas formas de manifestação, desde denúncias de preconceito feitas por atletas, torcedores e mídia até o racismo institucionalizado nas diversas modalidades esportivas. O racismo firma uma divisão entre raças humanas estabelecendo características comuns aos seus membros, relacionando as características físicas a aspectos morais, visando estabelecer uma hierarquia entre estas, de forma que uma seja considerada superior à outra (JACQUARD, 1988; GIDDENS, 2001; MUNANGA, 2003). No Brasil, a escravização de negros durou 300 anos e é uma marca histórica que, segundo Souza (2017), estrutura as relações de classe até os dias atuais se expressando em imensas desigualdades sociais quando se comparam as condições de vida de brancos e negros.

Os esportes historicamente atraíram as classes sociais subalternas devido, sobretudo, à possibilidade de ascensão social, uma vez que os esportes se tornaram espetáculos para o consumo de massa (LOPES, 2014). A grande visibilidade das práticas esportivas permite a exposição das desigualdades sociais presentes historicamente nas sociedades. Dentre tais desigualdades, o fenômeno do racismo apresenta-se como um dos desafios enfrentados por diversos atletas e profissionais negros engajados no mundo social do esporte. Em síntese, o acesso de negros e mestiços a determinados esportes é limitado, algumas modalidades são praticadas quase que exclusivamente pelas classes dominantes e, consequentemente, a presença de negros é praticamente inexistente (ASSUMPÇÃO et al., 2010). Os conflitos sociais decorrentes de preconceito racial, muitas vezes, misturam-se com questões de gênero e de classe (FERRETI; KNIJNIK, 2008). Inúmeros exemplos de racismo se multiplicam historicamente nos campos esportivos, impondo prejuízos sobretudo para atletas, torcedores, técnicos e gestores negros.

Nesse contexto, o presente artigo tem como objetivo analisar a produção científica internacional sobre o racismo no contexto esportivo profissional, identificando manifestações e modos característicos de como os racismos se expressam em diferentes modalidades. Nossa abordagem do tema racismo, aqui, será mediada pelas categorias "injúria racial" e "racismo institucional", que aglutinam boa parte da produção científica internacional sobre o assunto.

\section{METODOLOGIA}

Trata-se de uma pesquisa bibliográfica voltada para analisar as colaborações de diversos autores, no contexto internacional, sobre o tema do racismo no esporte. Foram consultadas as seguintes fontes de dados bibliográficas: Portal de Periódicos da Coordenação de Aperfeiçoamento de Pessoal de nível Superior (Portal da Capes) e as revistas indexadas nos estratos A1 a C da área de avaliação "Educação Física" da Plataforma Sucupira, dentro da classificação de periódicos no quadriênio 20132016. As referências duplicadas foram excluídas.

A pesquisa no Portal da Capes foi feita em dois momentos, para fins de fiabilidade: o primeiro nos dias 16, 23, 24 e 25 de junho de 2018, e o segundo no dia 
19 de outubro de 2018. Na Plataforma Sucupira a pesquisa foi realizada nos dias 14 , 15 e 16 de setembro de 2018 e nos dias 9, 10 e 11 de outubro de 2018.

Foram utilizados os seguintes descritores: racismo/racismo/racism, esportes/ deportes/sports, combinando os descritores pelos operadores lógicos AND, OR. As combinações dos descritores foram baseadas no idioma das revistas em que se realizou a busca. Foram analisados artigos publicados entre os anos de $2008 \mathrm{e}$ 2018. Os idiomas escolhidos para a busca de artigos foram português, espanhol e inglês. Foram excluídos artigos que, a partir do resumo, indicassem uma abordagem do tema racismo no esporte escolar e/ou universitário, estabelecendo então, como critério de inclusão, apenas as manifestações observadas no esporte profissional.

Os artigos selecionados foram analisados a partir de três categorias interpretativas: "injúria racial", "racismo institucional" e "história e produção social do racismo". A partir da divisão das publicações nessas categorias, foram identificadas diferentes maneiras pelas quais o racismo se expressa no contexto esportivo profissional, bem como quais dessas manifestações são mais abordadas nas produções científicas. Também foi realizada uma discussão sobre a diferença entre a literatura nacional e internacional, apontando lacunas existentes na produção de língua portuguesa. No presente artigo, abordamos as categorias interpretativas "racismo institucional" e "injúria racial". A categoria "história e produção social do racismo" será abordada aqui, por razões de adequação aos critérios de extensão do texto. No entanto, as três categorias de interpretação construíram-se interligadas. Desse modo, a reflexão subsidiada aqui já constitui uma visão ampla sobre o problema do racismo no esporte profissional e sobre os modos como é abordado na literatura científica internacional.

\section{RESULTADOS}

Foram encontrados, num primeiro momento, 150 artigos. Aplicando-se os critérios de exclusão estabelecidos neste trabalho, restaram 65 artigos a serem analisados. A Tabela 1 apresenta o resultado da pesquisa de acordo com os bancos de dados consultados.

Tabela 1 - Resultado da pesquisa por bancos de dados

\begin{tabular}{cc}
\hline Banco de dados & $\mathbf{N}^{\circ}$ de artigos \\
\hline CAPES & 78 \\
\hline Plataforma Sucupira & 28 \\
Estrato A1 & 24 \\
Estrato A2 & 13 \\
Estrato B1 & 2 \\
Estrato B2 & 4 \\
Estrato B4 & 1 \\
Estrato C & 1 \\
\hline
\end{tabular}

Fonte: os autores

A Tabela 2 apresenta o resultado da pesquisa utilizando os descritores combinados nos idiomas preestabelecidos pelo trabalho. 
Tabela 2 - Resultado da pesquisa por idiomas dos descritores

\begin{tabular}{c|c|c}
\hline Idioma & Descritores & No de artigos $^{\text {Racismo AND esportes }}$ \\
\hline Português & Racismo AND deportes & 3 \\
Espanhol & Racism AND sports & 136 \\
Inglês & Re & \\
\hline
\end{tabular}

Fonte: os autores

Após realizar uma pré-análise dos artigos encontrados, aplicando-se o critério de exclusão "duplicidade", foram excluídos 11 artigos. A Tabela 3 traça um panorama destes artigos, indicando as plataformas pesquisadas e os idiomas.

Tabela 3 - Artigos selecionados após pré-análise

\begin{tabular}{c|c|c|c|c|c|c}
\hline \multirow{2}{*}{} & \multirow{2}{*}{ CAPES } & \multicolumn{4}{|c}{ Plataforma Sucupira } \\
\cline { 3 - 7 } & 4 & A1 & A2 & B1 & B2 & B4 \\
\hline Português & 0 & 0 & 0 & 0 & 2 & 0 \\
Espanhol & 36 & 0 & 0 & 0 & 0 & 0 \\
Inglês & 40 & 6 & 6 & 8 & 0 & 3 \\
\hline Total & 40 & \multicolumn{5}{|c}{25} \\
\hline
\end{tabular}

Fonte: os autores

Analisando a Tabela 3, é possível observar que a maior parte da produção científica selecionada sobre o tema do racismo no esporte profissional é escrita em língua inglesa, tendo origem em diversos países do mundo. A literatura sobre o tema em português, dentro do recorte deste trabalho, se mostrou escassa, tendo apenas seis artigos disponíveis para análise. Referências na língua espanhola foram encontradas apenas num primeiro momento da pesquisa, tendo sido excluídas após a pré-análise. A Tabela 4 expõe a divisão dessas categorias, as temáticas inseridas em cada categoria e o número de artigos em cada temática.

Tabela 4 - Categorias de análise

\begin{tabular}{l|l|c}
\hline \multicolumn{1}{c|}{ Categorias } & \multicolumn{1}{|c}{ Temáticas de investigação } & $\mathbf{N}^{\circ}$ de artigos \\
\hline \multirow{3}{*}{ História e produção } & Resgate histórico & 14 \\
social do racismo & Trajetórias de atletas & 4 \\
& Análise estatística do racismo & 6 \\
& Influência da mídia & 8 \\
\hline \multirow{3}{*}{ Injúria racial } & Análise de casos & 6 \\
& Análise de comentários racistas & 3 \\
& Questões de raça e gênero & 3 \\
\hline \multirow{5}{*}{ Racismo institucional } & Programas de combate ao racismo & 5 \\
& Racismo nas organizações sociais ligadas ao esporte & 11 \\
& Baixa representatividade de técnicos negros & 3 \\
& Discriminação racial de árbitros esportivos & 2 \\
\hline
\end{tabular}

Fonte: os autores

Observando a Tabela 4 é possível perceber como os artigos selecionados se distribuem nas categorias de análise utilizadas no presente estudo. As temáticas de 
investigação expressam as subcategorias que se inter-relacionam e que permitem ter uma visão geral do material selecionado e dos modos como o tema racismo é abordado. Como dito anteriormente, focaremos nossa atenção, aqui, na discussão da literatura científica agrupada nas categorias "injúria racial" e "racismo institucional".

Ademais das categorias analíticas adotadas aqui para a interpretação da produção científica sobre o racismo nos esportes profissionais, a perspectiva antirracista no campo da Educação Física e do esporte, assumida neste artigo, pressupõe que as asserções racistas, as injúrias raciais e a visão depreciativa sobre as questões raciais têm aspectos comuns.

\section{INJÚRIA RACIAL NO ESPORTE}

Nesta categoria foram incluídos artigos cujas temáticas se relacionam com o racismo de maneira mais direta e perceptível. Dessa forma, foram estabelecidas divisões (análise de comentários racistas, análise de casos de injúria racial, questões de raça e gênero) a fim de compreender mais didaticamente como tem se expressado a produção científica neste aspecto.

Aobjetividade das manifestações de racismo já se mostra visível ao analisarmos o trabalho de Souza e colaboradores (2015), que investiga casos de injúria racial no futebol brasileiro tomando como base as situações envolvendo os jogadores Daniel Alves, Arouca, Aranha, Tinga, Roberto Carlos e também o árbitro de futebol Márcio Chagas da Silva. Os autores utilizaram informações obtidas de veículos da mídia sobre tais casos a fim de interpretar como o fenômeno do racismo repercute para além do imediatismo da injúria racial (SOUZA et al., 2015). O caso do atleta Tinga, inclusive, ilustra o trabalho de Lise e colaboradores (2015), que analisam o episódio ocorrido com o jogador durante um jogo entre Cruzeiro e Real Garcilaso, do Peru.

Souza et al. (2015) sugerem que, embora as ofensas sejam uma realidade passível de verificação através da mídia, parece haver um esforço das autoridades em minimizar os casos, tratando-os como de pouca importância, "casos isolados", e por isso não resultam em uma tomada de atitude no sentido de coibir manifestações desta natureza. Os trabalhos analisados apontam a brandura e excepcionalidade das penalidades no futebol brasileiro. Laruccia e Martyniuk (2016) apontam que o futebol brasileiro tem muito a falar sobre as relações sociais no país e que, como o esporte serviu como meio de ascensão social para negros e mestiços, houve um grande fortalecimento da ideia de democracia racial, ideia esta que acaba por afirmar o racismo diário da sociedade brasileira.

A dificuldade em estabelecer punições à altura para casos de discriminação racial parece ser um problema de escala global. Muitos dos trabalhos selecionados identificam esta mesma problemática. Para Doidge (2015), que aborda situações vividas pelo jogador Mario Balotelli no futebol italiano, a amenidade das punições sofridas pelos clubes envolvidos nos casos e a falta de mecanismos institucionais que combatam o racismo nos estádios da Itália dão destaque à necessidade de endurecer as punições, sejam elas multas, suspensões de torcidas ou eliminação dos clubes em competições (DOIDGE, 2015). 
Em outro artigo que aborda o racismo no futebol europeu, Renfrew e Snyder (2016) analisam o caso de racismo envolvendo o jogador uruguaio Luiz Suárez e o francês Patrice Evra. À ocasião, Suárez, que jogava no Liverpool FC, foi punido por usar ofensas raciais contra Patrice Evra, então jogador do Manchester United, durante um jogo válido pela Premier League, a primeira divisão do campeonato inglês de futebol. Os autores salientam que injúria racial é crime no Reino Unido e que muitos observadores se viram surpresos com este tipo de comportamento no futebol do país (RENFREW; SNYDER, 2016). Ainda no futebol inglês, outro caso que chamou atenção aconteceu em outubro de 2011, durante um jogo entre Chelsea e Queens Park Rangers (QPR), entre o então capitão do Chelsea (e da seleção inglesa) John Terry e o jogador Anton Ferdinand, do QPR. O caso é analisado por Gavins e Simpson (2015), que se dedicaram a investigar o desenrolar do julgamento de Terry. Os autores evidenciam que, em um primeiro momento, Terry foi julgado inocente pois, apesar da ofensa ter sido transmitida em rede nacional, o juiz que não entendeu como um comentário racista. Entretanto, após um ano do acontecido, o caso foi julgado novamente e o jogador foi condenado, multado e suspenso. Gavins e Simpson salientam que fatores externos foram fundamentais para esta reversão no caso, dentre eles, a análise que a mídia fez da expressão utilizada pelo jogador na situação, o que pode ter influenciado a opinião pública e o posicionamento das instituições responsáveis pelo futebol inglês (GAVINS; SIMPSON, 2015).

Tentando compreender como pensam os torcedores do futebol inglês, cenário recorrente nos estudos selecionados, o trabalho de Jamie Cleland (2014) utilizou a análise do discurso para interpretar comentários racistas nas redes sociais e fóruns sobre o esporte. Cleland analisou mais de 500 postagens e observou que o grande alvo do discurso racista é o multiculturalismo e, também, o islamismo; o imaginário de uma "raça pura" é constantemente alavancado. O autor aponta que esta manifestação dos torcedores nestas plataformas não é proibida por elas, sendo passível de contestação ou apoio, muito embora a maioria dos comentários que se seguem o rejeitem (CLELAND, 2014).

Tralci Filho e Santos (2017) também observaram a conduta dos torcedores nas redes sociais, analisando o comportamento de entusiastas de tênis, a partir de comentários feitos em textos publicados entre 2009 e 2016. Sendo o tênis um esporte com hegemonia de atletas brancos, muito devido ao seu particular espaço de prática, os autores identificaram que há também um discurso de pureza de raça, ao que chamaram de "hegemonia branca", principalmente ao comentar sobre o desempenho da atleta Serena Williams, que ocupava o segundo lugar no ranking mundial do esporte, à época. Mesmo sem referências diretas à etnia dos atletas, os autores puderam perceber a falta de validação de denúncias feitas por atletas negros acerca do preconceito no esporte e, também, o teor dos comentários sobre seus corpos. Outrossim, foi observado um resgate de discursos já cientificamente ultrapassados quanto ao desempenho dos atletas negros justificando-os com a teoria do racismo biológico (TRALCI FILHO; SANTOS, 2017).

No esforço de explorar as diversas formas nas quais o racismo pode se manifestar na linguagem da sociedade, Ferrucci e Tandoc (2017) estudaram a aplicação de estereótipos a quarterbacks da National Football League (NFL), 
a liga profissional de futebol americano dos EUA. Aplicando um questionário aos participantes da pesquisa, que eram em sua maioria homens brancos, os pesquisadores notaram que não houve o emprego de estereótipos aos jogadores brancos. No entanto, os jogadores negros foram rotulados de "fisicamente fortes" e "abençoados por natureza". Por fim, o artigo conclui que, embora a sociedade tenha evoluído a respeito das questões de raça, ainda há um forte apego a padrões raciais empregados em muitos contextos, inclusive no esporte (FERRUCCI; TANDOC, 2017).

Um prisma também examinado na produção científica é a relação entre questões de raça e questões de gênero. Utilizando o tênis como modalidade esportiva analisada, Cynthia Frisby (2017) realizou análise de matérias esportivas a fim de verificar a incidência de agressões racistas e sexistas contra Angelique Kerber e Serena Williams, atletas número um e dois do ranking mundial, respectivamente. A autora observou que Williams, mulher negra, é alvo mais frequente de ataques à sua etnia e seu gênero, embora Kerber também sofra insultos por seu gênero. O estudo destaca que mais pesquisas são necessárias para averiguar a profundidade das ofensas raciais direcionadas a atletas negras em todos os níveis de participação nos esportes (FRISBY, 2017). Harris e Berri (2016) analisam o racismo presente na liga profissional de basquete feminino dos EUA e destacam presença da discriminação frente a técnicos e atletas negras de basquete. Já Anderson e McCormack (2010) discutem como o esporte nutre discursos que ajudam a manter certos grupos em posições de subordinação, como é o caso de atletas negros e atletas gays.

\section{RACISMO INSTITUCIONAL}

Dentre as formas de manifestação do racismo estudadas pela literatura científica no recorte deste trabalho, uma das mais recorrentes é a do racismo institucional, que busca analisar como se dão as relações de poder no esporte e sua conexão com esta forma de discriminação.

Em consonância comalguns artigos citados no tópico anterior, uma preocupação frequente na literatura são os programas de combate ao racismo criados pelas instituições responsáveis pelas diferentes modalidades esportivas. Nesta perspectiva, Necati Cerrahoğlu (2016) analisa o plano criado pela UEFA intitulado "10 Point Action Plan" (Plano de Ação dos 10 Pontos) e sua aplicação no futebol turco. De acordo com o autor, embora as políticas de combate ao racismo implementadas no continente europeu tenham sido exitosas, dificuldades foram encontradas na Turquia. Neste país, nenhuma política foi desenvolvida de forma a colocar em prática, de maneira satisfatória, o plano da UEFA, o que, em sua opinião, reforçava a falta de interesse da mídia esportiva, do Ministério dos Esportes e da própria Federação de Futebol do país. Cerrahoğlu (2016) ainda ressalta que, apesar de o futebol movimentar grandes quantidades de dinheiro, poucos foram os investimentos destinados a criar medidas educacionais para torcedores turcos.

Dificuldade semelhante sofreu o programa "Show Racism The Red Card", programa criado pela Federação Inglesa de Futebol em conjunto com organizações antirracistas do país. Dixon, Lowes e Gibbons (2016) discutem sobre a eficácia do 
programa e sua sustentação financeira. São destacados os obstáculos enfrentados pelo programa, com o crescimento do conservadorismo ao redor do mundo, o que dificultou a arrecadação de fundos para programas como este. Em contrapartida, os pesquisadores destacam o papel da mídia no fortalecimento da mensagem antirracista no esporte e o próprio multiculturalismo existente no futebol inglês, que emprega atletas de várias nacionalidades (DIXON; LOWES; GIBBONS, 2016).

Procurando entender as manifestações de racismo no futebol espanhol e as políticas de combate à discriminação racial na Espanha, Llopis-Goig (2009) analisa sociologicamente o fenômeno do racismo, faz uma conexão com suas expressões nos estádios do país e investiga as iniciativas antirracistas organizadas tanto pela sociedade civil como por grandes companhias e instituições. O autor também comenta sobre ações do governo em resposta a tais iniciativas, destacando a criação de um órgão específico para averiguar estas questões no país, o Observatório do Racismo e Violência no Esporte. O autor conclui seu trabalho destacando o crescimento do racismo no país e o esforço que deverá ser feito pelas instituições para lutar contra este problema (LLOPIS-GOIG, 2009).

Ainda observando o comportamento do racismo no continente europeu, Müller, Van Zoonen e De Roode (2008) investigaram a campanha "Stand Up Speak Up”, da empresa esportiva Nike, e a sua contribuição para o combate ao racismo no futebol holandês, averiguando seus efeitos em jogadores de futebol e torcedores. A campanha foi analisada em seu aspecto discursivo e visual, observando sua conexão com os agentes envolvidos no esporte. De forma geral os autores entendem que os potenciais efeitos positivos da campanha não foram totalmente absorvidos pelo público, na questão discursiva, pois o entendimento do senso comum sobre o racismo em muito se distinguia do que o que a campanha abordava. Para os autores, a comunicação desta campanha apresentava limitações (MÜLLER; VAN ZOONEN; DE ROODE, 2008).

Outro olhar sobre a questão das políticas de combate ao racismo é dado na pesquisa de Solow, Solow e Walker (2011), que versa sobre a "Rooney Rule", regra da National Football League (NFL) que obriga os times da liga a entrevistarem pelo menos um candidato pertencente a grupos étnicos minoritários em seu processo de contratação. Os autores buscaram identificar se a etnia é um fator determinante para a contratação para o cargo de técnico principal dos times. O trabalho conclui que, embora exista esta regra, o número de técnicos principais pertencentes a grupos étnicos minoritários não aumentou na liga no período de 1970 a 2009, sugerindo uma necessidade de elaborar novas estratégias para aumentar o número de negros em cargos de prestígio nos esportes (SOLOW; SOLOW; WALKER, 2011).

Mantendo o foco dos estudos na NFL, dois trabalhos se dedicaram a examinar o acesso de negros a cargos de prestígio na liga (DUFUR; FEINBERG, 2009; BRADDOCK; SMITH; DAWKINS, 2012). Os trabalhos analisam dados da NFL a fim de traçar um panorama sobre a realidade de membros de grupos étnicos minoritários na liga de futebol americano. Dufur e Feinberg (2009) investigaram o processo de contratação de atletas universitários pelos clubes profissionais e chegaram à conclusão de que atletas negros sofrem mais discriminação simbólica desde o 
momento inicial na liga, recebendo um tratamento discriminatório percebido como prejudicial, em relação a atletas brancos. Já Braddock, Smith e Dawkins (2012) se empenharam em estudar a admissão de negros em outros cargos nos clubes da liga, como os cargos de técnico e de gestão, analisando dados de todos os técnicos ativos na liga durante as temporadas de 2000 e 2006. Os autores observaram que a etnia do profissional parece afetar diretamente na contratação para cargos de autoridade nas franquias. Os pesquisadores destacam que há escassez de atletas negros em posições importantes no esporte, como quarterbacks e centers, e sugerem que uma vez que não há muitos atletas negros nessas posições em campo, também não haverá técnicos negros para estas posições no futuro, criando um efeito cascata nas oportunidades de emprego para estes indivíduos.

Concentrando a atenção nas principais ligas esportivas norte-americanas, cinco trabalhos se complementam ao investigar variadas formas de racismo institucional na National Basketball Association (NBA). Riguang Wen (2018), em seu trabalho "Does Racial Discrimination Exist Within the NBA? An Analysis Based on Salary-per-Contribution", investiga se há de fato uma diferença salarial na liga de acordo com a etnia dos atletas utilizando como base a relação entre salário anual e contribuição do atleta ao time, com a finalidade de estabelecer um índice passível de análise mais objetiva. Os autores concluíram que entre 1999 e 2016 este índice foi muito maior para atletas negros do que para atletas brancos, tendo aumentado consideravelmente após 2006. Também foi observada uma disparidade entre jogadores que são negros, americanos, veteranos e entre jogadores brancos nas mesmas condições. A pesquisa conclui que os resultados vão de encontro com a literatura existente, uma vez que esta considera apenas o salário absoluto dos atletas e não sua contribuição para as franquias. Por fim, o trabalho constata que a NBA não apresenta mais discriminação racial no sentindo financeiro, mas que isto não indica necessariamente que os jogadores negros não sofram algum tipo de discriminação oriunda da própria sociedade americana (WEN, 2018).

Conservando o campo do basquete norte-americano, Agyemang e Singer (2014) esmiuçaram entrevistas com cinco funcionários de uma franquia da NBA com o objetivo de compreender suas perspectivas sobre raça e racismo tanto nos esportes americanos como na sociedade em geral. Importante salientar que a pesquisa foi realizada após o primeiro mandato de Barack Obama, o primeiro presidente negro dos Estados Unidos da América, o que pode ter sugestionado uma diferente concepção sobre estes temas na comunidade do país. Os autores chegaram à conclusão de que o tema do racismo é de fato um assunto persistente na liga e na sociedade, e que os jogadores pensam em como lidar com essas questões no futuro (AGYEMANG; SINGER, 2014).

Em "'Goodbye to the Gangstas': the NBA Dress Code, Ray Emery, and the Policing of Blackness in Basketball and Hockey", Lorenz e Murray (2014) observaram outra configuração do racismo dentro das instituições. Investigando a principal liga de basquete NBA e a liga profissional de hóquei, a National Hockey League (NHL), os autores estudaram as representações de "negritude" em ambas as ligas e sua relação com as formas de racismo da sociedade norte-americana contemporânea. 
O trabalho aponta que, apesar das diferenças na composição racial das duas ligas, ambas se esforçaram de igual maneira para policiar e disciplinar jovens atletas negros, coibindo manifestações espontâneas de suas culturas. Os autores também salientam no trabalho que as representações do homem negro como "ameaçador", "criminoso" e "perigoso" foram bastante veiculadas na mídia esportiva (LORENZ; MURRAY, 2014).

Observando as formas de discriminação racial provenientes de altos escalões das organizações esportivas, dois trabalhos apresentam casos específicos relacionados a grandes empresários, proprietários de franquias da NBA, que apresentaram postura racista dentro do espaço do esporte. O primeiro caso, descrito no trabalho de Gill Jr, Christensen e Pérez (2017), relata o caso de racismo de Bruce Levenson e Danny Ferry, ex-proprietários do Atlanta Hawks, contra um funcionário da empresa. Os autores analisaram a repercussão do caso na mídia esportiva e investigaram se a venda da franquia em questão representou uma assunção de culpa dos envolvidos. O trabalho relata que, apesar de a NBA ter um histórico de severas decisões contra casos de racismo na liga, neste caso em específico pouco foi feito e Levenson e Ferry não só saíram ilesos, como "transformaram" esta acusação de racismo em um lucro de $\$ 610$ milhões de dólares ao vender o time (GILL JR; CHRISTENSEN; PÉREZ, 2017).

Outro trabalho que expõe caso de racismo institucional de um ex-proprietário de uma franquia da NBA é o artigo de Hylton e Lawrence (2016), que trata do caso de Donald Sterling, então dono do Los Angeles Clippers, e seus comentários racistas. Os autores utilizam os conceitos de "frontstage racism" para identificar o preconceito que é visível ao público, e o conceito de "backstage racism" para se referir ao que acontece nas estruturas das instituições. A pesquisa relata que muitos saíram em defesa de Sterling na mídia, apesar de seus indefensáveis comentários, e conclui que, embora esta forma de racismo deva ser combatida, é necessária também uma atenção maior ao racismo estrutural, que acaba por gerar manifestações de ordem pública (HYLTON; LAWRENCE, 2016).

Abordando o futebol, alguns trabalhos se esforçaram em analisar o tema da ausência de negros em cargos de prestígio neste esporte. Steven Bradbury (2013) examina esta problemática no futebol europeu entrevistando 20 sujeitos de 13 países diferentes com a finalidade de examinar a extensão e as formas com que o racismo institucional impactou desproporcionalmente ao limitar indivíduos de grupos étnicos minoritários de atingir estas posições. $O$ autor discute que essas práticas são sustentadas por padrões de "hegemonia branca", aliadas às estruturas já existentes das instâncias de poder do futebol. Por fim, o artigo sugere meios de contornar e desconstruir a prática do racismo institucional e do privilégio branco, ampliando a legitimidade do futebol no continente europeu (BRADBURY, 2013). Já Smith e Hattery (2011) promoveram estudo analisando como a etnia do profissional pode influenciar sua carreira como dirigente esportivo. Os autores investigaram a baixa representatividade de homens negros em cargos importantes nas associações esportivas, o que, segundo os pesquisadores, contrasta com a grande contribuição destes indivíduos enquanto atletas, sustentando inclusive a própria indústria que 
Ihes nega oportunidades de empregos no futuro. $\mathrm{O}$ artigo conclui com sugestões de políticas públicas e práticas para promover a diversidade racial nas instituições esportivas (SMITH; HATTERY, 2011). Jamie Cleland e Ellis Cashmore (2013) também discutiram sobre a carência de dirigentes negros no futebol, utilizando como campo o futebol inglês profissional. Os autores analisaram respostas a um questionário online de torcedores, jogadores e ex-jogadores de futebol, brancos e de grupos étnicos minoritários. De posse destes dados, mil respostas foram examinadas pelos autores, e os resultados indicaram que a maioria dos participantes acreditava que o racismo operava no nível executivo do futebol profissional. Enquanto alguns acusaram proprietários de clubes de discriminar deliberadamente candidatos para os cargos, outros acreditavam que o racismo é uma estrutura produzida pela sociedade ao duvidar da capacidade de pessoas negras de exercerem cargos de prestígio. A pesquisa conclui mostrando que muitos participantes acreditam ser importante a existência de uma regulamentação no sentido de favorecer a contratação de profissionais de minorias étnicas, tal como a "Rooney Rule" da NFL (CLELAND; CASHMORE, 2013).

Em harmonia com o trabalho de Bradbury (2013), duas pesquisas de RankinWright, Hylton e Norman (2016; 2017) investigaram como organizações esportivas do Reino Unido têm lidado com questões de igualdade de raça e diversidade para cargos de técnico. Em um artigo de 2016 os autores realizaram uma entrevista semiestruturada objetivando entender as perspectivas das instituições sobre raça, etnicidade, igualdade racial e "branqueamento". Destaca-se na pesquisa que há um "daltonismo social" em prática que reforça a ideia de que a etnia não é um fator determinante para sustentar a desigualdade existente entre técnicos negros e brancos. O artigo afirma que estas práticas reforçam o racismo institucional e servem para normalizar e privilegiar a "branquitude", e que o entendimento sobre raça e igualdade racial no Reino Unido deve se focar em pesquisas, políticas públicas e práticas, de forma que membros de grupos étnicos minoritários sejam considerados para atuação como técnicos esportivos (RANKIN-WRIGHT; HYLTON; NORMAN, 2016). Em outro trabalho, os mesmos autores discutem processos que envolvem gênero e raça e que reforçam disparidades entre técnicos esportivos através das experiências de técnicos negros no Reino Unido. Entrevistando técnicos de duas organizações esportivas, os pesquisadores interpretam narrativas dos entrevistados visando entender a complexidade em que questões de raça, etnia e gênero são vividas por técnicos esportivos. Os discursos elaborados pelos profissionais entrevistados destacam a necessidade de que agentes do esporte reconheçam as relações estruturais que limitam o avanço na carreira destes técnicos, diminuindo assim as desigualdades de raça e gênero (RANKIN-WRIGHT; HYLTON; NORMAN, 2017).

Ainda no intuito de analisar a problemática da baixa representatividade de técnicos negros, o trabalho intitulado "The under-representation and experiences of elite level minority coaches in professional football in England, France and the Netherlands", de Bradbury, Van Sterkenburg e Mignon (2018), se empenhou em investigar a ausência de técnicos negros na França, Inglaterra e Holanda. Após analisar dados de 40 entrevistas de técnicos de grupos étnicos minoritários, a pesquisa identificou uma série de fatores que limitam a continuidade da carreira 
destes profissionais. Os autores identificaram as informações mais presentes nesta discussão e observaram que o acesso limitado, as experiências negativas no ambiente de trabalho e também a escolha dos times em contratar profissionais já conhecidos ao invés de levar em consideração todos os possíveis candidatos são fatores influenciam na progressão da carreira de técnicos de grupos étnicos minoritários (BRADBURY; VAN STERKENBURG; MIGNON, 2018).

Uma temática também presente em nossa revisão de literatura sobre o racismo nos esportes é discriminação racial de árbitros esportivos. Dois artigos, mais estritamente, abordam esse assunto. O artigo "Further examination of potential discrimination among MLB umpires", de Tainsky, Mills e Winfree (2015), busca verificar a existência de discriminação racial entre árbitros da Major League Baseball (MLB), a liga de beisebol profissional dos EUA. Os autores buscaram identificar tendências dos árbitros em prejudicar os atletas com base em suas etnias, observando momentos do jogo cuja análise do árbitro é fundamental para a manutenção do jogador em campo. O trabalho não encontrou resultado conclusivo sobre a existência deste tipo de discriminação de árbitros a partir da metodologia utilizada no trabalho (TAINSKY; MILLS; WINFREE, 2015).

O trabalho de Wagner-Egger, Gygax e Ribordy (2012) analisou a percepção de jogadores de futebol, torcedores e árbitros a respeito de um determinado lance de jogo, com especial preocupação em observar o juízo feito pelos árbitros. Os autores dividiram os participantes da pesquisa em três grupos (jogadores, torcedores e árbitros) e Ihes pediram para analisar as "divididas" de um jogo de futebol (situação onde dois jogadores disputam a posse de bola). Os grupos tiveram acesso a imagens que apresentavam jogadores negros e brancos nas posições de "agressor" e "vítima". Os resultados do trabalho mostram que de fato houve uma diferenciação: alguns participantes julgaram mais rapidamente como "falta" o lance quando se tratava de um jogador negro na posição de "agressor". Entretanto, quando o jogador branco estava nesta mesma posição, os participantes julgavam a "falta" como sendo mais grave. Por fim, o trabalho conclui que não há diferença significativa na interpretação dos grupos participantes, sugerindo que os efeitos observados foram independentes de etnia, habilidade dos jogadores e, principalmente, se o julgamento foi feito pelos participantes do grupo de árbitros (WAGNER-EGGER; GYGAX; RIBORDY, 2012).

A discussão sobre a categoria "racismo institucional" revela aspectos de como o racismo tem se configurado no interior de instituições esportivas em diversos contextos e como tais instituições têm se mobilizado diante de tal problema social. Ressalta-se aqui a importante relação que cada campo esportivo em particular estabelece com outros campos sociais, de modo a constituir-se ora como espaço social de reprodução de desigualdades sociais existentes nos países analisados, ora como um espaço de ruptura e de promoção de relações mais igualitárias. Nesse contexto, a análise dos artigos agrupados nesse conjunto permite-nos afirmar que o racismo está presente de modo incisivo nas instituições relacionadas ao esporte profissional e que as iniciativas de combate ao racismo, ainda que apresentem relativo êxito, ainda enfrentam enormes desafios. 


\section{CONSIDERAÇÕES FINAIS}

Dentro dos critérios estabelecidos por esta pesquisa, pode-se destacar o volume de trabalhos encontrados sobre o tema do racismo no esporte profissional e, também, a variedade de abordagens empregadas pelos pesquisadores no esforço de analisar o fenômeno nas suas mais diversas manifestações. Pudemos observar, durante a análise dos dados, que as temáticas de investigação por vezes se complementam se considerarmos os enfoques ou os objetos de estudo investigados pelos pesquisadores. Alguns trabalhos poderiam ser distribuídos para outras temáticas ou categorias, mas examinando a metodologia dos estudos é possível compreender a disposição nestes grupos.

Fato que chamou a atenção no decorrer da pesquisa foi a discrepância percebida entre os idiomas pesquisados. Os artigos em língua inglesa foram maioria absoluta entre os trabalhos totais selecionados, totalizando 136 (totais) e 58 artigos (após a pré-análise). As publicações em língua portuguesa e língua espanhola se mostraram escassas, uma vez que 11 artigos em português foram encontrados e apenas seis seguiram para a discussão da pesquisa. Outra peculiaridade desta pesquisa é que, durante a busca de artigos para análise, nenhum trabalho de revisão foi encontrado, com a procura resultando apenas em trabalhos originais, o que evidencia a importância da realização de trabalhos de tal natureza visando analisar o que tem sido produzido sobre o tema na esfera acadêmica. O estado destas pesquisas sugere uma vasta exploração sobre o tema do racismo nos esportes, muito embora as temáticas referentes ao assunto sejam as mais diversas, trabalhos como este são úteis para categorizar estas abordagens, possibilitando maior clareza na pesquisa sobre o racismo nos esportes.

\section{REFERÊNCIAS}

AGYEMANG, Kwame J.A; SINGER, John N. Race in the present day: NBA employees sound off on race and racism. Journal of African American Studies, v. 18, n. 1, p. 11-32, 2014. Disponível em: https://www.jstor.org/stable/43525532? seq=1 Acesso em: 7 set. 2020.

ALDERMAN, Derek H.; INWOOD, Joshua. Mobility as antiracism work: The "hard driving" of NASCAR's Wendell Scott. Annals of the American Association of Geographers, v. 106, n. 3, p. 597-611, 2016. Disponível em: https://www.tandfonline.com/doi/ 00045608. 2015.1118339? scroll=top\&needAccess=true\&journalCode=raag21 Acesso em: 7 set. 2020.

ANDERSON, Eric; MCCORMACK, Mark. Comparing the black and gay male athlete: patterns in American oppression. The Journal of Men's Studies, v. 18, n. 2, p. 145-158, 2010. Disponível em: https://journals.sagepub.com/doi/10.3149/jms.1802.145. Acesso em: 7 set. 2020.

ASSUMPÇÃO, Luís Otávio Teles et al. Temas e questões fundamentais na sociologia do esporte. Revista Brasileira de Ciência e Movimento, v. 18, n. 2, p. 92-99, 2010. Disponível em: https://portalrevistas.ucb.br/index.php/RBCM/article/view/1154. Acesso em: 7 set. 2020.

BRADBURY, Steven. Institutional racism, whiteness and the under-representation of minorities in leadership positions in football in Europe. Soccer \& Society, v. 14, n. 3, p. 296314, 2013. Disponível em: https://www.tandfonline.com/doi/abs/10.1080/14660970.2013.801 262. Acesso em: 7 set. 2020. 
BRADBURY, Steven; VAN STERKENBURG, Jacco; MIGNON, Patrick. The underrepresentation and experiences of elite level minority coaches in professional football in England, France and the Netherlands. International Review for the Sociology of Sport, v. 53, n. 3, p. 313-334, 2018. Disponível em: https://journals.sagepub.com/ doi/10.1177/1012690216656807. Acesso em: 7 set. 2020.

BRADDOCK, Jomills Henry; SMITH, Eryka; DAWKINS, Marvin P. Race and pathways to power in the National Football League. American Behavioral Scientist, v. 56, n. 5, p. 711-727, 2012. Disponível em: https://miami.pure.elsevier.com/en/publications/race-andpathways-to-power-in-the-national-football-league. Acesso em: 7 set. 2020.

CERRAHOĞLU, Necati. A Case Analysis of the Turkish Football in regard to the UEFA's 10-Point Action Plan against Racism. International Journal of Progressive Education, v. 12, n. 1, p. 136-146, 2016. Disponível em: https://ijpe.penpublishing.net/makale/25. Acesso em: 7 set. 2020.

CLELAND, Jamie; CASHMORE, Ellis. Football fans' views of racism in British football. International Review for the Sociology of Sport, v. 51, n. 1, p. 27-43, 2013. Disponível em: https://journals.sagepub.com/doi/abs/10.1177/1012690213506585. Acesso em: 7 set. 2020.

CLELAND, Jamie. Racism, football fans, and online message boards: How social media has added a new dimension to racist discourse in English football. Journal of Sport and Social Issues, v. 38, n. 5, p. 415-431, 2014. Disponível em: https://journals.sagepub.com/doi/ abs/10.1177/0193723513499922. Acesso em: 7 set. 2020.

DIXON, Kevin; LOWES, Jacqueline; GIBBONS, Tom. Show Racism The Red Card: potential barriers to the effective implementation of the anti-racist message. Soccer \& Society, v. 17, n. 1, p. 140-154, 2016. Disponível em: https://www.tandfonline.com/doi/full/10.1080/1466097 0.2014.919280. Acesso em: 7 set. 2020.

DOIDGE, Mark. 'If you jump up and down, Balotelli dies': Racism and player abuse in Italian football. International Review for the Sociology of Sport, v. 50, n. 3, p. 249-264, 2015. Disponível em: https://journals.sagepub.com/doi/abs/10.1177/1012690213480354. Acesso em: 7 set. 2020.

DUFUR, Mikaela J.; FEINBERG, Seth L. Race and the NFL draft: Views from the auction block. Qualitative Sociology, v. 32, n. 1, p. 53-73, 2009. Disponível em: https://link.springer. com/article/10.1007/s11133-008-9119-8. Acesso em: 7 set. 2020.

FERRETTI, Marco Antônio de Carvalho; KNIJNIK, Jorge Dorfman. Preconceito de gênero, raça e sexualidade no tênis: tudo isso porque ela tem o corpo para ser uma atleta e não uma modelo fotográfica. In: ENCONTRO DA ALESDE: ESPORTE NA AMÉRICA LATINA: ATUALIDADE E PERSPECTIVAS, 1., 2008, Curitiba. Anais... Curitiba: UFPR, 2008. Disponível em: http://www.alesde.ufpr.br/encontro/artigos.html. Acesso em: 7 set. 2020.

FERRUCCI, Patrick; TANDOC, Edson C. Race and the deep ball: Applying stereotypes to NFL quarterbacks. International Journal of Sport Communication, v. 10, n. 1, p. 41-57, 2017. Disponível em: https://journals. humankinetics.com/view/journals/ijsc/10/1/article-p41. xml. Acesso em: 7 set. 2020.

FRISBY, Cynthia M. A content analysis of Serena Williams and Angelique Kerber's racial and sexist microagressions. Open Journal of Social Sciences, v. 5, n. 05, p. 263, 2017. Disponível em: https://www.scirp.org/journal/paperinformation.aspx?paperid=76372. Acesso em: 7 set. 2020.

GAVINS, Joanna; SIMPSON, Paul. Regina v John Terry: The discursive construction of an alleged racist event. Discourse \& Society, v. 26, n. 6, p. 712-732, 2015. Disponível em: https://journals.sagepub.com/doi/abs/10.1177/0957926515592783. Acesso em: 7 set. 2020. 
GIDDENS, Anthony. Sociologia. 6. ed. Lisboa: Fundação Calouste Gulbenkian, 2001.

GILL JR, Emmett L.; CHRISTENSEN, M. Candace; PÉREZ, Alfred G. The sale of the Atlanta Hawks: is it racism or white ownership playing the race card?. Journal of Sports Media, $v$. 12, n. 1, p. 113-140, 2017. Disponível em: https://muse.jhu.edu/article/664340/pdf. Acesso em: 7 set. 2020.

HARRIS, Jill; BERRI, David J. If you can't pay them, play them: fan preferences and ownrace bias in the WNBA. International Journal of Sport Finance, v. 11, n. 3, p. 247, 2016. Disponível em: https://go.gale.com/ps/s?id=GALE\%7CA466413314\&sid=googleScholar\&v=2

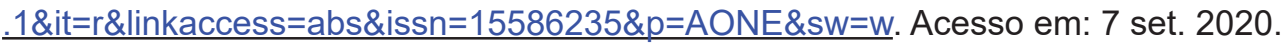

HYLTON, Kevin; LAWRENCE, Stefan. 'For your ears only!'Donald Sterling and backstage racism in sport. Ethnic and Racial Studies, v. 39, n. 15, p. 2740-2757, 2016. Disponível em: https://www.tandfonline.com/doi/abs/10.1080/01419870.2016.1177193. Acesso em: 7 set. 2020.

JACQUARD, Albert. Elogio da diferença. São Paulo: Martins Fontes, 1988.

LARUCCIA, Mauro Maia; MARTYNIUK, Valdenise Leziér. Racism in football: a narrative path. Advances in Journalism and Communication, v. 4, p. 103-112, 2016. Disponível em: https://papers.ssrn.com/sol3/papers.cfm?abstract id=3026973. Acesso em: 7 set. 2020.

LISE, Riqueldi S.; SOUZA, Maria Theresa O.; JENSEN, Larissa; CAPRARO, André M. O caso tinga: analisando (mais) um episódio de racismo no futebol sul-americano. Pensar a Prática, v.18, n.4, 2015. https://doi.org/10.5216/rpp.v18i4.32123

LLOPIS-GOIG, Ramon. Racism and Xenophobia in Spanish football: facts, reactions and policies. Physical Culture and Sport. Studies and Research, v. 47, n. 1, p. 35-43, 2009. Disponível em: http://cejsh.icm.edu.pl/cejsh/element/bwmeta1.element.doi-10_2478 v10141-009-0030-0. Acesso em: 7 set. 2020.

LOPES, Felipe. Esporte e classe social na sociologia de Pierre Bourdieu. Revista Espaço e Ética, v.1, n.3, p.168-182, 2014.

LORENZ, Stacy L.; MURRAY, Rod. "Goodbye to the Gangstas" The NBA dress code, Ray Emery, and the policing of blackness in basketball and hockey. Journal of Sport and Social Issues, v. 38, n. 1, p. 23-50, 2014. Disponível em: https://journals.sagepub.com/ doi/10.1177/0193723513491750. Acesso em: 7 set. 2020.

MÜLLER, Floris; VAN ZOONEN, Liesbet; DE ROODE, Laurens. We can't 'Just do it' alone! An analysis of Nike's (potential) contributions to anti-racism in soccer. Media, Culture \& Society, v. 30, n. 1, p. 23-39, 2008. Disponível em: https://journals.sagepub.com/ doi/10.1177/0163443707084348. Acesso em: 7 set. 2020.

MUNANGA, Kabengele. Uma abordagem conceitual de noções de raça, racismo e etnia. In: SEMINÁRIO DE RELAÇÕES RACIAIS E EDUCAÇÃO, 3., 2003, Rio de Janeiro. [Palestra proferida]. Rio de Janeiro: PENESB, 2003.

RANKIN-WRIGHT, Alexandra J.; HYLTON, Kevin; NORMAN, Leanne. Off-colour landscape: Framing race equality in sport coaching. Sociology of Sport Journal, v. 33, n. 4, p. 357368, 2016. Disponível em: http://dro.dur.ac.uk/26001/. Acesso em: 7 set. 2020.

RANKIN-WRIGHT, Alexandra J.; HYLTON, Kevin; NORMAN, Leanne. Negotiating the coaching landscape: Experiences of Black men and women coaches in the United Kingdom. International Review for the Sociology of Sport, p. 1012690217724879, 2017. Disponível em: https://journals.sagepub.com/doi/ abs/10.1177/1012690217724879?ai=1gvoi\&mi=3ricys\&af=R. Acesso em: 7 set. 2020. 
RENFREW, Daniel; SNYDER, Genesis M. "When Said with a Sneer": translating language, race, and culture through an English football race controversy. City \& Society, v. 28, n. 3, p. 319-340, 2016. Disponível em: https://anthrosource.onlinelibrary.wiley.com/doi/abs/10.1111/ ciso.12095. Acesso em: 7 set. 2020.

SMITH, Earl; HATTERY, Angela. Race relations theories: implications for sport management. Journal of Sport Management, v. 25, n. 2, p. 107-117, 2011. Disponível em: https://journals. humankinetics.com/view/journals/jsm/25/2/article-p107.xml. Acesso em: 7 set. 2020.

SOLOW, Benjamin L.; SOLOW, John L.; WALKER, Todd B. Moving on up: The Rooney rule and minority hiring in the NFL. Labour Economics, v. 18, n. 3, p. 332-337, 2011. Disponível em: https://ideas.repec.org/a/eee/labeco/v18y2011i3p332-337.html. Acesso em: 7 set. 2020.

SOUZA, Jessé. A elite do atraso: da escravidão à lava-jato. Rio de Janeiro: Leya, 2017.

SOUZA, Maria Thereza Oliveira et al. Injúria racial no futebol brasileiro: uma análise sóciohistórica de alguns casos (não tão) esporádicos ocorridos nos últimos anos. Motrivivência, v. 27 , n. 46, p. 230-240, 2015. Disponível em: https://periodicos.ufsc.br/index.php/ motrivivencia/article/view/2175-8042.2015v27n46p230. Acesso em: 7 set. 2020.

TAINSKY, Scott; MILLS, Brian M.; WINFREE, Jason A. Further examination of potential discrimination among MLB umpires. Journal of Sports Economics, v. 16, n. 4, p. 353-374, 2015. Disponível em: https://journals.sagepub.com/doi/abs/10.1177/1527002513487740. Acesso em: 7 set. 2020.

TRALCI FILHO, Marcio Antonio; SANTOS, Alessandro de Oliveira dos. O discurso da supremacia branca e o esporte: um estudo a partir de textos e comentários na internet. Movimento, v. 23, n. 1, p. 229-247, 2017. Disponível em: https://seer.ufrgs.br/ Movimento/article/view/64497. Acesso em: 7 set. 2020.

WAGNER-EGGER, Pascal; GYGAX, Pascal; RIBORDY, Farfalla. Racism in soccer? perception of challenges of black and white players by white referees, soccer players, and fans. Perceptual and motor skills, v. 114, n. 1, p. 275-289, 2012. Disponível em: https:// pubmed.ncbi.nlm.nih.gov/22582695/. Acesso em: 7 set. 2020.

WEN, Riguang. Does racial discrimination exist within the NBA? an analysis based on salary-per-contribution. Social Science Quarterly, v. 99, n. 3, p. 933-944, 2018. Disponível em: https://onlinelibrary.wiley.com/doi/abs/10.1111/ssqu.12485. Acesso em: 7 set. 2020. 
Abstract: Racism is a sociocultural phenomenon with remarkable expression in sports. This study analyzes scientific works on racism in professional sports published between 2008 and 2018. Searches were performed on two databases: Portal da CAPES and journals indexed on the Sucupira Platform' evaluation area of 'Physical Education.' Sixty-five articles were selected and divided into the categories 'racial slur' and 'institutional racism.' Several cases of racial slurs are analyzed and illustrate how racism has hampered black athletes' careers in several sports. At institutional level, campaigns against racism are analyzed, as well as racist forms of discrimination present in sports such as football, basketball, baseball and American football. We highlight the variety of approaches, the relevance of the studies and the importance of the topic for addressing racism in the studied sports fields.

Keywords: Racism. Difamation. Social oppression. Athletes

Resumen: El racismo es un fenómeno sociocultural que tiene una notable expresión en el deporte. El objetivo de esta investigación fue analizar la producción científica internacional sobre el racismo em los deportes profesionales entre 2008 y 2018. La búsqueda se realizó en dos bases de datos: Portal de la CAPES y revistas indexadas en el área de evaluación "Educación Física" de la Plataforma Sucupira. Fueron seleccionados 65 artículos que son analizados a partir de las categorías "insulto racial" y "racismo institucional". Varios casos de injuria racial son analizados e ilustran las formas en que el racismo ha puesto obstáculos a las trayectorias de los atletas negros en diversas modalidades. A nivel institucional, se analizan campañas contra el racismo, así como formas racistas de discriminación presentes en deportes como fútbol, baloncesto, béisbol y fútbol americano. Destacamos la variedad de enfoques, la relevancia de los estudios y la importancia del tema para enfrentar el racismo en los campos deportivos estudiados.

Palabras clave: Racismo. Difamación. Opresión social. Atletas. 


\section{LICENÇA DE USO}

Este é um artigo publicado em acesso aberto (Open Access) sob a licença Creative Commons 4.0 (CC BY), que permite uso, distribuição e reprodução em qualquer meio, desde que o trabalho original seja corretamente citado, sem restrição inclusive o uso para fins comerciais.

\section{CONFLITO DE INTERESSES}

Os autores declararam que não há conflito de interesses neste trabalho.

\section{CONTRIBUIÇÕES AUTORAIS}

Lennon Giulio Santos de Farias: concepção do estudo, delimitação metodológica, busca nas bases de dados, leitura e analise dos artigos, interpretação dos dados, elaboração do relatório geral da pesquisa, revisão da versão final do artigo.

Léo Barbosa Nepomuceno: concepção do estudo, delimitação metodológica, supervisão e orientação nas buscas nas bases de dados, leitura e analise dos artigos, interpretação dos dados, crítica do relatório geral da pesquisa, revisão da versão final do artigo.

Luiz Sanchez Neto: delimitação metodológica, orientação nas buscas nas bases de dados , crítica do relatório geral da pesquisa, revisão da versão final do artigo.

Eduardo Vinícius Mota e Silva: crítica do relatório geral da pesquisa, revisão da versão final do artigo.

\section{FINANCIAMENTO}

O presente trabalho foi realizado sem qualquer apoio financeiro.

\section{COMO REFERENCIAR}

FARIAS, Lennon Giulio Santos de; NEPOMUCENO, Léo Barbosa; SANCHEZ NETO, Luiz; SILVA, Eduardo Vinícius Mota e. A institucionalização do racismo contra negros(as) e as injúrias raciais no esporte profissional: o contexto internacional. Movimento, v.26, p. e26074, jan./dez. 2020. Disponível em: https:// seer.ufrgs.br/Movimento/article/view/104354 Acessado em: 10 out. 2020. DOI: https://doi.org/10.22456/1982-8918.104354

\section{RESPONSÁVEIS EDITORIAIS}

Alex Branco Fraga*, Elisandro Schultz Wittizorecki*, Ivone Job*, Mauro Myskiw*, Raquel da Silveira*

*Universidade Federal do Rio Grande do Sul, Escola de Educação Física, Fisioterapia e Dança, Porto Alegre, RS, Brasil 